\title{
The reasons why fractional flow reserve and instantaneous wave-free ratio are similar using wave separation analysis
}

\author{
Soohong Min ${ }^{1}$, Gwansuk Kang ${ }^{2}$, Dong-Guk Paeng ${ }^{1,3}$ and Joon Hyouk Choi ${ }^{4^{*}}$ (])
}

\begin{abstract}
Background and objectives: Fractional flow reserve (FFR) and instantaneous wave-free ratio (iFR) are the two most commonly used coronary indices of physiological stenosis severity based on pressure. To minimize the effect of wedge pressure $\left(P_{\text {wedge }}\right)$, FFR is measured during hyperemia conditions, and iFR is calculated as the ratio of distal and aortic pressures $\left(P_{d} / P_{a}\right)$ in the wave-free period. The goal of this study was to predict $P_{\text {wedge }} u$ sing the backward wave $\left(P_{\text {back }}\right)$ through wave separation analysis (WSA) and to reflect the effect of $P_{\text {wedge }}$ on FFR and iFR to identify the relationship between the two indices.

Methods: An in vitro circulation system was constructed to calculate $P_{\text {wedge. }}$. The measurements were performed in cases with stenosis percentages of 48,71 , and $88 \%$ and with hydrostatic pressures of 10 and $30 \mathrm{mmHg}$. Then, the correlation between $\mathrm{P}_{\text {back }}$ by WSA and $\mathrm{P}_{\text {wedge }}$ was calculated. In vivo coronary flow and pressure were simultaneously measured for 11 vessels in all patients. The FFR and iFR values were reconstructed as the ratios of forward wave at distal and proximal sites during hyperemia and at rest, respectively.
\end{abstract}

Results: Based on the in vitro results, the correlation between $P_{\text {back }}$ and $P_{\text {wedge }}$ was high $(r=0.990, p<0.0001)$. In vivo results showed high correlations between FFR and reconstructed FFR $(r=0.992, p<0.001)$ and between iFR and reconstructed iFR $(r=0.930, p<0.001)$.

Conclusions: Reconstructed FFR and iFR were in good agreement with conventional FFR and iFR. FFR and iFR can be expressed as the variation of trans-stenotic forward pressure, indicating that the two values are inferred from the same formula under different conditions.

Keywords: Wave intensity analysis (WIA), Fractional flow reserve (FFR), Instantaneous wave-free ratio (IFR), Coronary artery, Wave separation analysis (WSA)

\section{Background}

Fractional flow reserve (FFR) is considered the "gold standard" among invasive physiological diagnostic methods for determining the percutaneous coronary intervention of intermediate lesions in patients with stable angina [1]. Therefore, FFR was used as a comparative group

\footnotetext{
*Correspondence: valgom@naver.com

${ }^{4}$ Department of Cardiology, Jeju National University School of Medicine, Jeju National University Hospital, Jeju, Korea

Full list of author information is available at the end of the article
}

for instantaneous wave-free ratio (iFR) in some studies. In these studies, iFR has been reported to be faster, less uncomfortable, and not inferior compared to FFR [2, 3].

To explain FFR theoretically, coronary wedge pressure $\left(\mathrm{P}_{\text {wedge }}\right)$ is a very important factor. FFR is measured when $\mathrm{P}_{\text {wedge }}$ is minimized by pharmacological hyperemia [4]. The $\mathrm{P}_{\text {wedge }}$ wave is characterized by rapid decline in and formation of baseline in pre-systole [5]. This event is explained by backward-propagating suction-waves in wave intensity analysis (WIA) and loss 
of the Windkessel effect due to occlusion $[6,7]$. The Windkessel effect is defined as the condition where the pressure does not fall to zero due to capacitive elements and resistance [8]. If iFR can also be explained by $\mathrm{P}_{\text {wedge }}$ or backward wave through wave separation analysis (WSA), we can explain how the two indices are similar or different. Thus, iFR could be measured when $\mathrm{P}_{\text {wedge }}$ is minimized during the wave-free period of diastole without hyperemia.

This study was based on the assumption that coronary pressure waves can be separated into constituent forward $\left(\mathrm{P}_{\text {for }}\right)$ and backward $\left(\mathrm{P}_{\text {back }}\right)$ waves using WSA. We attempted to prove this assumption as follows: (1) $\mathrm{P}_{\text {back }}$ can replace $\mathrm{P}_{\text {wedge }}$ from an in vitro experimental study; and (2) FFR and iFR can be reconstructed using $\mathrm{P}_{\text {back }}$ obtained from WSA and compared with conventional FFR and iFR from in vivo measurement results. This study may be the first to identify similarities and differences between FFR and iFR using WSA.

\section{Experiment and method}

Theoretical background

The iFR is defined as the ratio of distal pressure $\left(\mathrm{P}_{d}\right)$ to aortic pressure $\left(\mathrm{P}_{a}\right)$ at rest during a wave-free period, as shown in Eq. 1:

$$
\mathrm{iFR}=\frac{\mathrm{P}_{d}}{\mathrm{P}_{a}} \text { at rest during wave-free period }
$$

Assuming that $\mathrm{P}_{\text {wedge }}$ or $\mathrm{P}_{\text {back }}+\mathrm{P}_{\text {static }}$ is baseline in the wave-free period, the slopes of $\mathrm{P}_{d}$ and $\mathrm{P}_{a}$, and $\mathrm{P}_{\text {for }}$ (prox) and $\mathrm{P}_{\text {for }}$ (dist) in pre-systolic phase could be the same, as shown in Fig. 1. Thus, reconstructed iFR is redefined as follows in Eq. 2:

$$
\begin{aligned}
\text { reconstructed iFR } & =\frac{\mathrm{P}_{d}-\left(\mathrm{P}_{\text {back }}+\mathrm{P}_{\text {static }}\right)}{\mathrm{P}_{a}-\left(\mathrm{P}_{\text {back }}+\mathrm{P}_{\text {static }}\right)} \\
& \approx \frac{\mathrm{P}_{\text {for }}(\text { dist })}{\mathrm{P}_{\text {for }}(\text { prox })}(\text { at resting })
\end{aligned}
$$
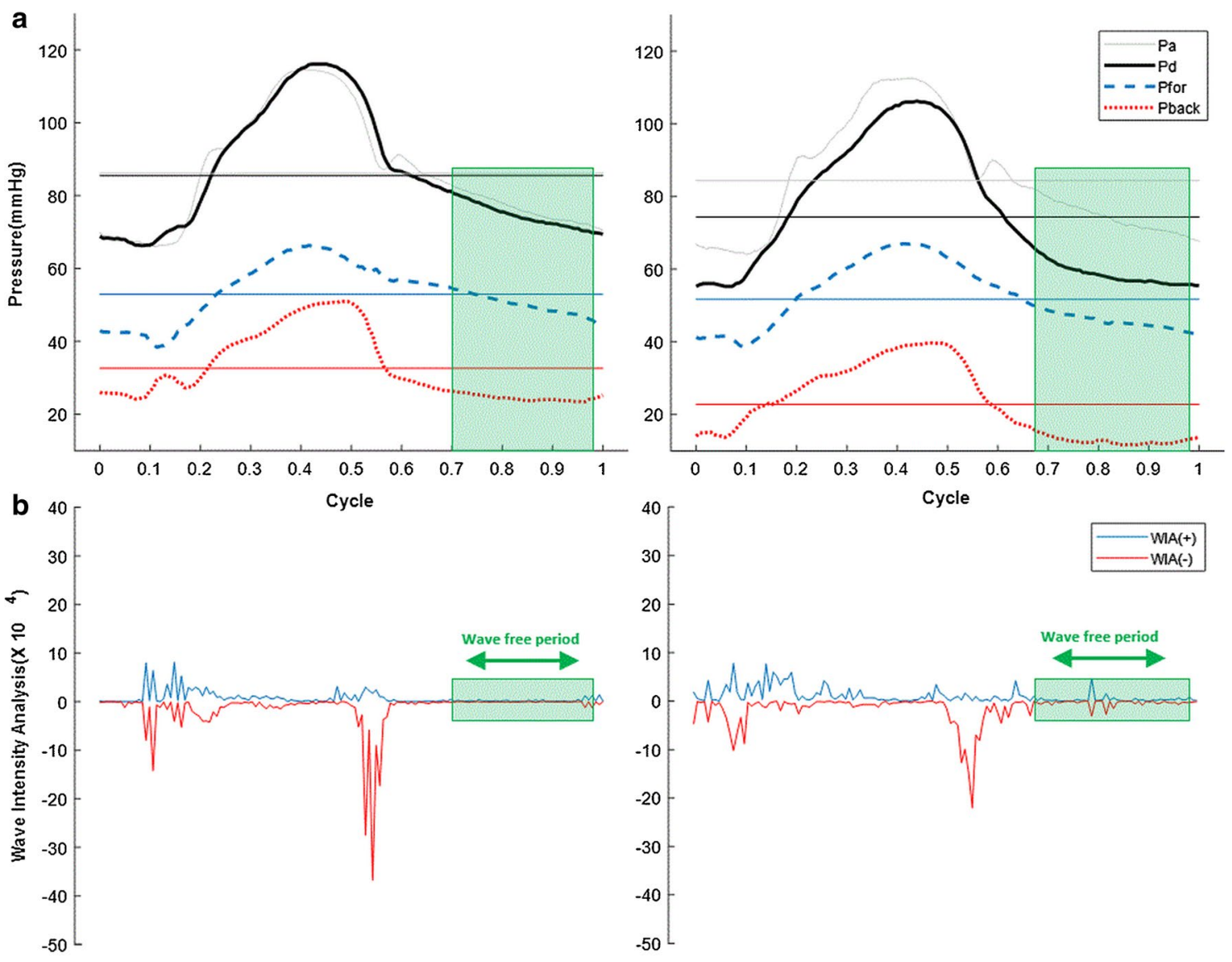

Resting

Hyperemia

Fig. 1 Changes in pressures before and after Hyperemia and wave free period extraction through WIA analysis. a Aortic and distal pressures $\left(P_{a}\right.$ $\left.P_{d}\right)$, forward and backward waves $\left(P_{\text {forr }} P_{\text {back }}\right)$ in a cycle at pre-hyperemia and hyperemia, and horizontal lines are their average values over a cycle. $\mathrm{P}_{a}$ decreased little but $\mathrm{P}_{d}$ decreased more at hyperemia. Although overall $\mathrm{P}_{\text {back }}$ decreases a lot at hyperemia, there is little change in $\mathrm{P}_{\text {for }}$ between pre-hyperemia and hyperemia. $\mathbf{b}$ Wave free period was extracted through wave intensity analysis (WIA) as shown in green boxes 
Reconstructed iFR is calculated as the average pressure of an entire cycle at rest and is not the same as conventional iFR, which is determined only in the wavefree period. Reconstructed iFR, which is the ratio of $\mathrm{P}_{\text {for }}$ at distal and proximal locations averaged over a whole cycle, is assumed to be similar to conventional iFR. This assumption will be shown to be appropriate by in vitro and in vivo experimental results in this study.

The corresponding FFR of the coronary artery $\left(F F R_{c o r}\right)$ is overestimated based on central vein pressure $\left(\mathrm{P}_{v}\right)$ instead of $\mathrm{P}_{\text {wedge }}$ considering collateral flow [4]. FFR cor is defined as the ratio of distal pressure $\left(\mathrm{P}_{d}\right)$ and aortic pressure $\left(\mathrm{P}_{a}\right)$ when the effect of $\mathrm{P}_{\text {wedge }}$ is subtracted at hyperemia as shown in Eq. 3:

$$
F F R_{\text {cor }}=\frac{\mathrm{P}_{d}-\mathrm{P}_{\text {wedge }}}{\mathrm{P}_{a}-\mathrm{P}_{\text {wedge }}}(\text { at hyperemia })
$$

Reconstructed FFR is the ratio of $\mathrm{P}_{\text {for }}$ at the distal and proximal locations when $\mathrm{P}_{\text {wedge }}$ is assumed to be $\mathrm{P}_{\text {back }}+\mathrm{P}_{\text {static }}$ as shown in Eq. 4:

$$
\begin{aligned}
\text { reconstructed FFR } & =\frac{\mathrm{P}_{d}-\left(\mathrm{P}_{\text {back }}+\mathrm{P}_{\text {static }}\right)}{\mathrm{P}_{a}-\left(\mathrm{P}_{\text {back }}+\mathrm{P}_{\text {static }}\right)} \\
& =\frac{\mathrm{P}_{\text {for }}(\text { dist })}{\mathrm{P}_{\text {for }}(\text { prox })}(\text { at hyperemia })
\end{aligned}
$$

WIA was performed to obtain wave-free periods using representative flow speed $(\mathrm{U})$ and pressure $(\mathrm{P})$ as in Eqs. 5 and 6:

$$
\begin{aligned}
& \mathrm{WI}(+)=\frac{1}{4 \rho c}\left(\frac{d P}{d t}+\rho c \frac{d U}{d t}\right)^{2} \\
& \mathrm{WI}(-)=\frac{1}{4 \rho c}\left(\frac{d P}{d t}-\rho c \frac{d U}{d t}\right)^{2}
\end{aligned}
$$

where $\rho$ is the density of blood $\left[1050 \mathrm{~kg} / \mathrm{m}^{-3}\right]$, and $\mathrm{c}$ is wave speed $[\mathrm{m} / \mathrm{s}]$ calculated using the single-point equation. The wave-free period is defined as the time from WI $(-)=0$ to the end of diastole for $5 \mathrm{~ms}$ [7].

WSA was performed to obtain $\mathrm{P}_{\text {for }}$ and $\mathrm{P}_{\text {back }}$ using representative flow $(\mathrm{F}(\mathrm{t}))$ and pressure $(\mathrm{P}(\mathrm{t}))$ obtained from Eqs. 7 and 8:

$$
\begin{aligned}
& \mathrm{P}_{f o r}(t)=\frac{\left[P(t)+Z_{c} \times F(t)\right]}{2} \\
& \mathrm{P}_{\text {back }}(t)=\frac{\left[P(t)-Z_{c} \times F(t)\right]}{2}
\end{aligned}
$$

where $Z_{c}$ is characteristic impedance and is defined as an input impedance $\left(Z_{i}\right)$ in the absence of wave reflection.
$\mathrm{Z}_{i}$ is defined as resistance or impedance obtained by frequency analysis of representative pressure and blood flow using Fourier analysis [9]. At the same time, the modulus (division) and phase (subtraction) of impedance were automatically calculated. Therefore, the impedance modulus at zero frequency (0-impedance) is mean pressure/ mean flow. There are many methods of obtaining $Z_{c}$. In general, $Z_{c}$ is defined as the modulus at the zero crossing point or a point close to zero in phase. The reason for this distinction is that the negative phase is the imaginary component of Fourier analysis. Previous studies have addressed $Z_{c}$ with a fixed frequency [9-15]. However, $Z_{c}$ can be changed depending on the situation [9]. In this study, we used flexible $Z_{c}$, which is defined as the average modulus of four harmonics of the fundamental frequency after zero crossing or close to zero in phase less than $10 \mathrm{~Hz}$. The process of calculating the reconstructed FFR and iFR is briefly shown in Fig. 2.

\section{In vitro coronary artery circulation system}

In this study, we designed an in vitro coronary blood circulation system. As shown in Fig. 3, a catheter (Combo Wire XT ${ }^{\circledR}$, Volcano Corporation, San Diego, CA, USA) was inserted into a tube to simultaneously measure pressure and flow speed at the proximal and distal sites of stenosis. A pulsatile pump (Model 55-3305, Harvard Apparatus Corp., USA) was used to mimic heart motion. The pump rate was fixed to 60 rotations $/ \mathrm{min}$, and the operative phase ratio (OPR; systolic time over a cyclic time) was set to $60 \%$. The tube was filled with $1.5 \mathrm{~L}$ of Doppler fluid (Model 707, ATS Laboratories, USA). The viscosity of this fluid $(5 \mathrm{cP})$ is similar to that of human blood. The tube was an IXAK ${ }^{\circledR}$ silicon tube (SL-0710, TOMMYHECO, KOREA) with an internal diameter of $5 \mathrm{~mm}$. To reflect stenotic coronary arteries in the system, stenotic vessels of 48,71 , and $88 \%$ (minimum vessel area/maximum vessel area) were created using a threedimensional printer. The minimal luminal dimensions of each model were 28,46 , and 64\%. A Windkessel model was constructed using an air tank to control blood flow, pressure waveforms, and phase differences, which were similar to those observed in the human coronary artery. This approach can eliminate negative pressure and exerts zero flow on the system. Measurements were performed at $20 \mathrm{~mm}$ proximal to the stenosis site, and a catheter was inserted $200 \mathrm{~mm}$ proximal to the site of stenosis.

We created three conditions. Figure $3 \mathrm{a}$ is the basal condition. There is a combination of forward and backward pressures in the coronary artery. Resistance with stenosis can be used to control the ratio of forward and backward flow. By adjusting the inner diameter of the resistor, the amount of fluid directed to the stenotic phantom can be adjusted. Therefore, the ratio of forward and backward 


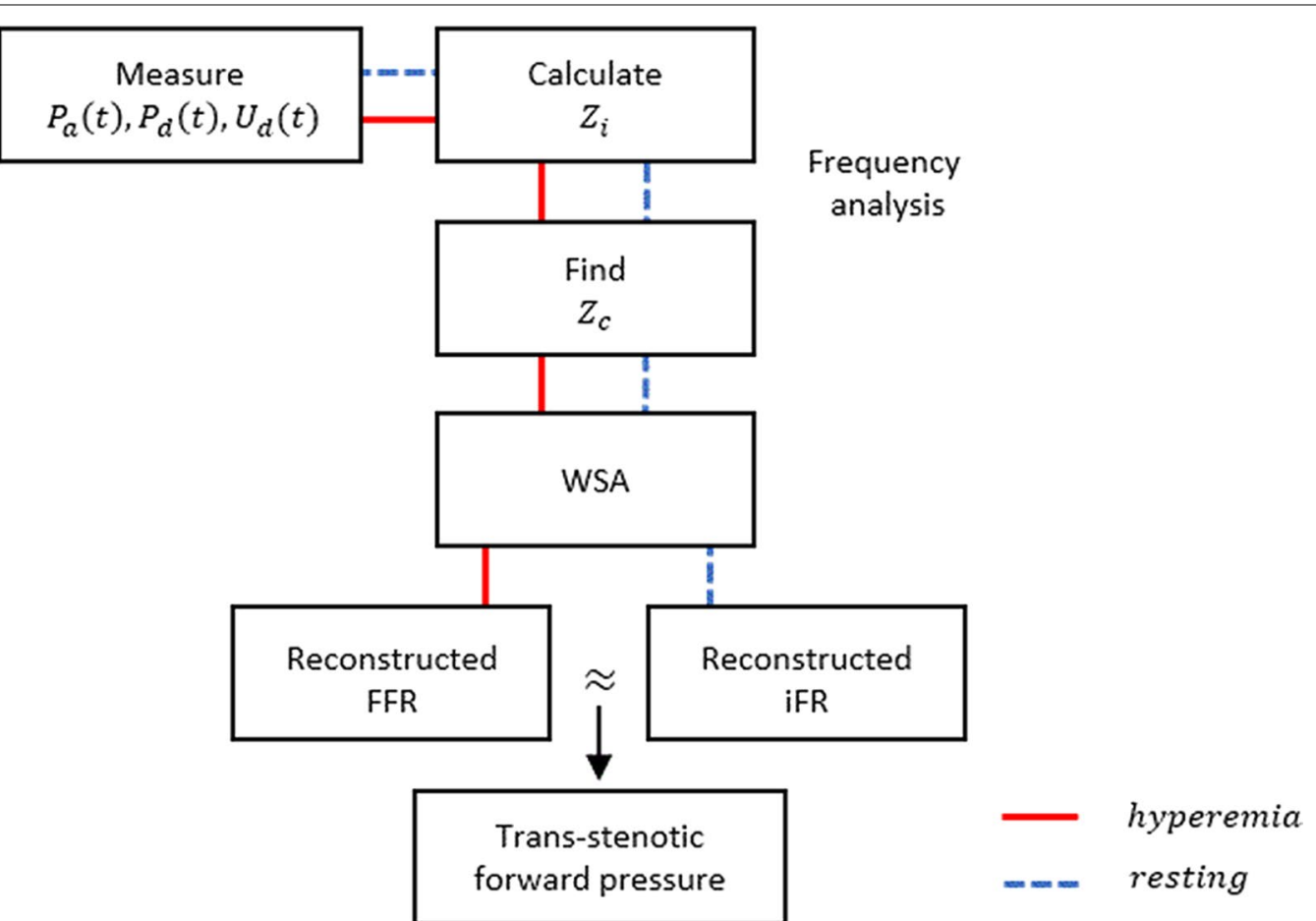

Fig. 2 Schematic diagram of the process of calculating reconstructed FFR and iFR. Measure $P_{a^{\prime}} P_{d^{\prime}} U_{d^{\prime}}$ divide $P_{d}$ by $U_{d^{\prime}}$ calculate $Z_{i}$ and find $Z_{c}$ through frequency analysis of $Z_{i}$. $P_{\text {back }}$ is calculated through WSA. Reconstructed FFR and iFR are calculated by the same formula using trans-stenotic forward pressure at hyperemia and rest conditions, respectively

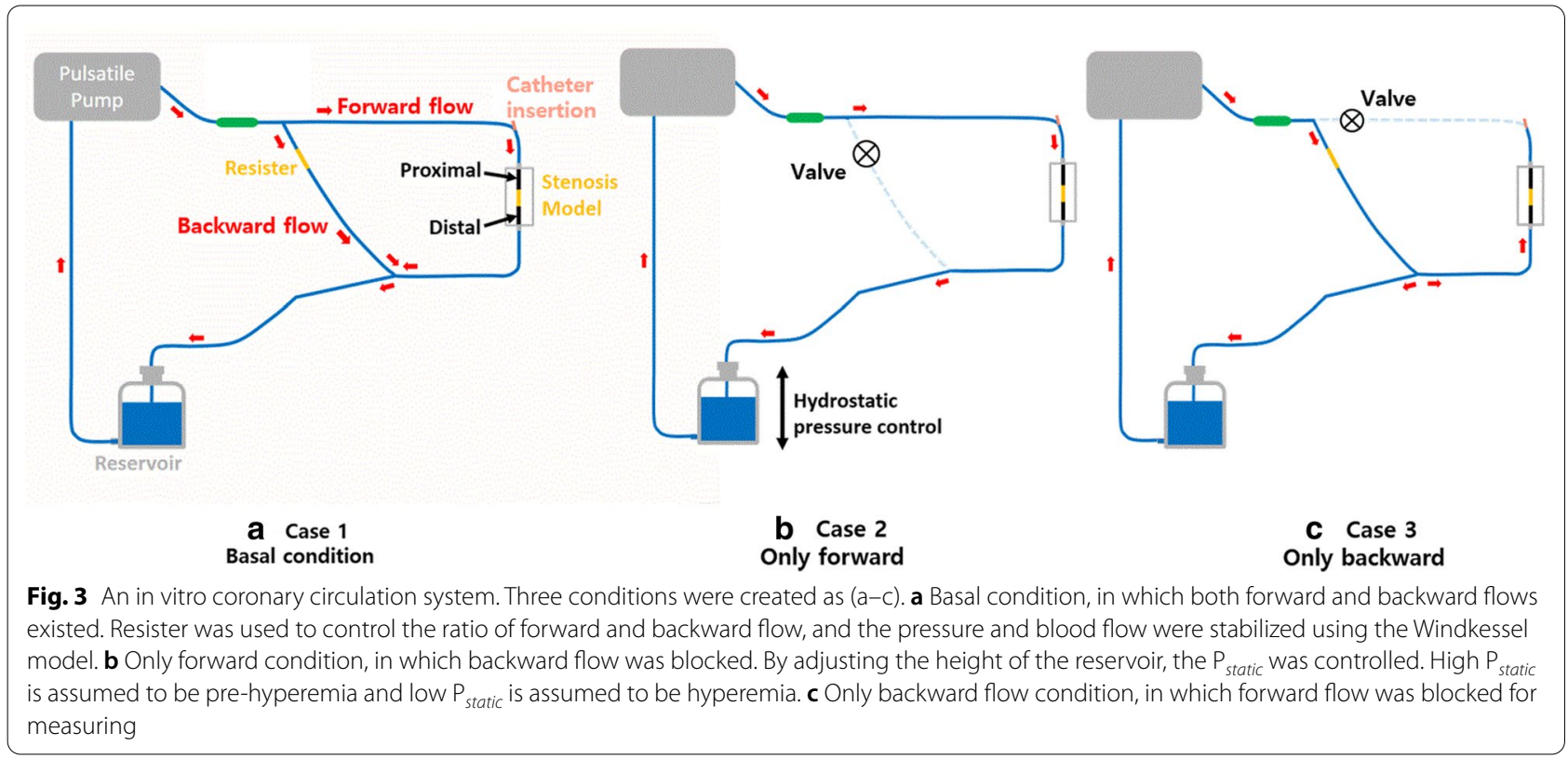

flow can be controlled, which makes it possible to reproduce a human-like automatic control ability of the blood flow. If the inner diameter of the resistor is larger than that of each site of stenosis, a phenomenon occurs where the backward flow is larger than the forward flow. Forward and backward pressures were separated using WSA 
in this condition. The reservoir was used to control $\mathrm{P}_{\text {static }}$ in the blood flow system, which was adjusted by varying the height.

Figure $3 \mathrm{~b}$ is a condition of forward flow only without backward flow. High $\mathrm{P}_{\text {static }}$ and low $\mathrm{P}_{\text {static }}$ values are assumed to represent pre-hyperemia and hyperemia conditions, respectively. $\mathrm{P}_{d} / \mathrm{P}_{a}$ values measured in pre-hyperemia and hyperemia conditions were assumed to indicate reconstructed iFR and reconstructed FFR, respectively.

To confirm that this in vitro circulatory system mimics the blood flow of the coronary system, the flow speed of Case 2 (only forward condition) was divided by that of Case 1 (basal condition), and the ratio was compared to the coronary flow reserve.

Figure 3c depicts the $\mathrm{P}_{\text {wedge }}$. In clinical practice, $\mathrm{P}_{\text {wedge }}$ is measured at a distal site when the artery is blocked with a balloon. To reflect this in the in vitro system, we blocked the branch point toward the coronary phantom through the valve. The measured pressure in this case was compared with the backward pressure that was calculated using WSA.

\section{In vivo experiment}

The study protocol was approved by the institutional review board of Jeju National University Hospital (2016-07-011).

Coronary angiography and pressure-flow measurements were obtained using standard techniques [16]. Angiographic views were obtained following administration of intracoronary nitrate in all cases $(200$ or $300 \mu \mathrm{g})$. We used 0.014-inch pressure and Doppler sensor-tipped wires (ComboWire XT, Volcano Corporation, San Diego, CA, USA). The distal pressure was set to zero and equalized to the aortic pressure at the coronary ostium before being positioned at least three vessel diameters distal to the site of stenosis. Adenosine was administered for hyperemia by intravenous infusion based on 11 measurements $(140 \mu \mathrm{g} / \mathrm{kg} / \mathrm{min})$. When a ComboWire was used, the electrocardiogram, pressures, and flow velocity signals were directly extracted from the digital archive of the device console (ComboMap, Volcano Corporation). Data were analyzed off-line, using a custom software package designed by Labview (National Instruments, Austin, TX, USA). Stenosed vessels were defined as vessels that had an angiographically visible stenosis from 40 to $70 \%$ severity, as determined visually by an operating physician at the time of coronary angiography.

Resting indices were calculated at a time of stability, allowing for a return to stable baseline conditions after any preceding injection of contrast or saline. Hyperemic indices were determined during stable hyperemia, excluding cases with ectopy or conduction delay. Representative flow and pressure waves were obtained by an average method using recordings of 5-15 consecutive cycles both at rest and during hyperemia. These procedures were necessary to achieve linearity and time invariance. FFR and iFR were calculated as the ratio of mean $\mathrm{P}_{d}$ to $\mathrm{P}_{a}$ at hyperemia during a whole cycle and at rest during a wave-free period, respectively.

The reconstructed FFR and reconstructed iFR were calculated by the following equation of $\left(\mathrm{P}_{d}-\mathrm{P}_{\text {back }}\right) /\left(\mathrm{P}_{a}-\mathrm{P}_{\text {back }}\right)$ at hyperemia and at rest conditions, respectively.

\section{Statistical analysis}

All statistical analyses were performed using the Statistical Package for the Social Sciences (SPSS), version 23.0 software (SPSS Statistics for Macintosh, IBM Corp. Armonk, NY, USA). The values of continuous variables are mean and standard deviation (SD), and categorical variables are expressed as frequency and percentage. The comparison of continuous variables between groups was performed using the independent sample t-test, and the categorical variables were assessed with a chi-square test. The correlation analysis between groups was performed by simple correlation analysis. For each statistic, the significance level was less than 0.05 .

\section{Result}

Parts of this study were presented to the ACC.19: The American College of Cardiology 68th Annual Scientific Sessions, New Orleans, USA, March 16-18, 2019 [17, 18].

\section{In vitro experiment}

A total of 18 cases were analyzed according to stenoses (48, 71, and $88 \%)$, and $\mathrm{P}_{\text {static }}(10$ and $30 \mathrm{mmHg}$ ) values obtained from mock circulatory experiments. The measured and calculated data are summarized in Table 1.

When the static pressure was $10 \mathrm{mmHg}$, the distal flow ratio (only forward flow/basal flow) according to stenosis increased to $2.2,1.5$, and 1.2 as the stenosis increased to 49,71 , and $88 \%$, respectively. When the static pressure was $30 \mathrm{mmHg}$, the distal flow ratios were $2.5,1.6$, and 1.2 at stenosis rates of 49,71 , and $88 \%$, respectively.

The $P_{d} / P_{a}$ ratio for Case 1 decreased in the order of stenosis $(48,71$, and $88 \%)$ at each $\mathrm{P}_{\text {static }}(10 \mathrm{mmHg}, 0.81$, $0.64,0.46 ; 30 \mathrm{mmHg}, 0.91,0.88,0.60$, respectively). The distal flow ratio in high $\mathrm{P}_{\text {static }}$ was higher than that in low $\mathrm{P}_{\text {static }}$.

The $P_{d} / P_{a}$ ratio for Case 2 decreased in the order of stenosis $(48,71$, and $88 \%)$ at each $\mathrm{P}_{\text {static }}(10 \mathrm{~mm} \mathrm{Hg}, 0.90$, 0.84 , and $0.5 ; 30 \mathrm{mmHg}, 1.00,0.96$, and 0.67 , respectively). The change in $P_{d} / P_{a}$ between Case 1 and Case 2 was larger for low $\mathrm{P}_{\text {static }}$ than for high $\mathrm{P}_{\text {static }}$, as shown in Fig. 4. 


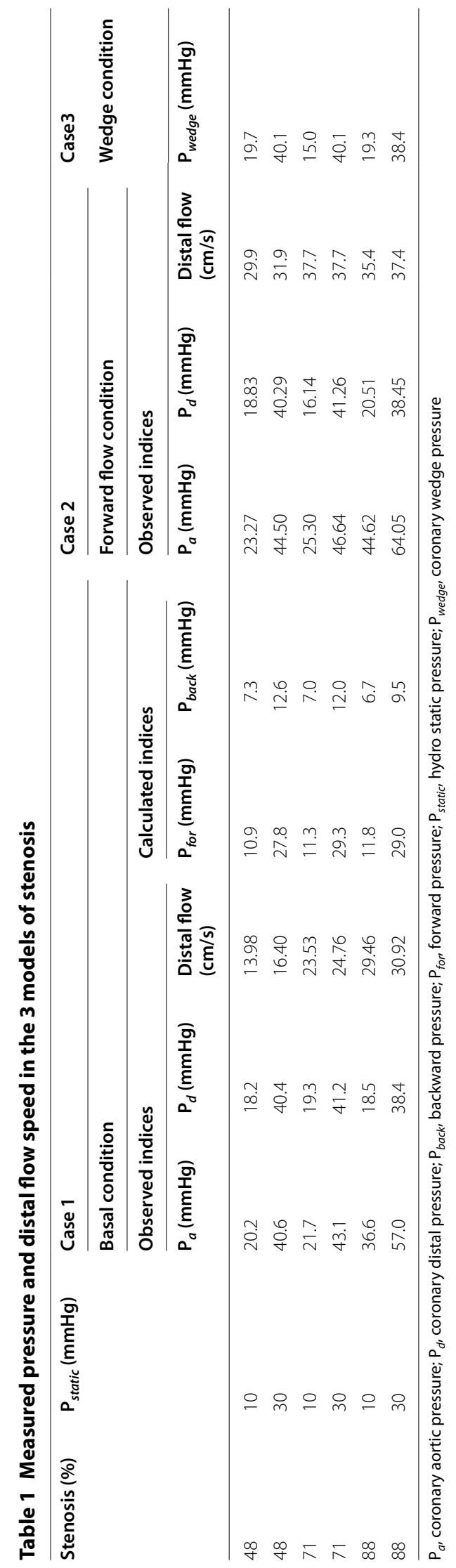


The waveforms and magnitude of the observed $\mathrm{P}_{\text {wedge }}$ and $\mathrm{P}_{\text {back }}+\mathrm{P}_{\text {static }}$ were very similar (Fig. 5). This trend was also observed in other cases. $\mathrm{P}_{\text {wedge }}$ always contains static pressure. Correlation with the $\mathrm{P}_{\text {back }}+\mathrm{P}_{\text {static }}$ and $\mathrm{P}_{\text {wedge }}$ was high $(\mathrm{r}=0.990, p<0.0001$, Fig. 6$)$, and the slope was 1.0612 .

\section{In vivo experiment}

Nine patients in whom we were able to simultaneously measure blood flow and blood pressure in the proximal and distal regions were compared with pre- and posthyperemia values of distal forward pressure $\mathrm{P}_{f o r}$ and distal backward pressure $\mathrm{P}_{b a c k}$ using $\mathrm{Z}_{c}$ in 11 coronary blood vessels. The results are summarized in Table 2 .
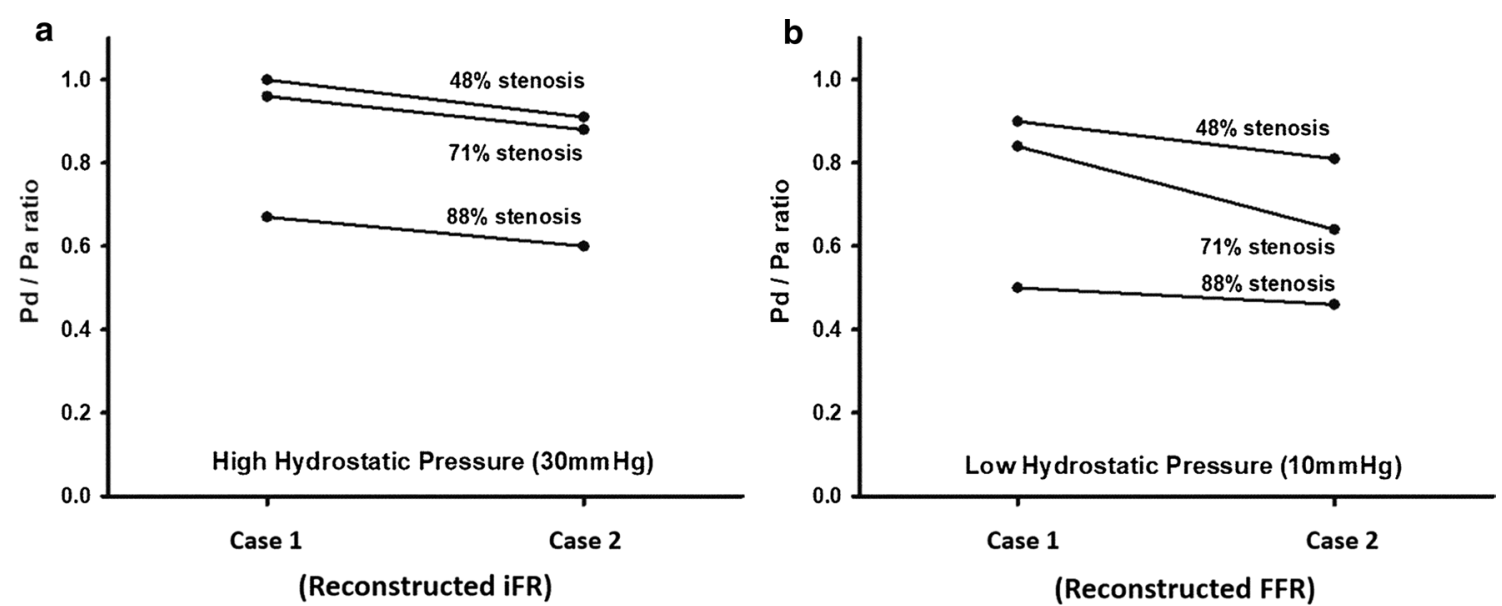

Fig. $4 \mathrm{P}_{d} \mathrm{P}_{a}$ in Case 1 and 2 at 3 stenosis when $\mathrm{P}_{\text {static }}$ was 30 and $10 \mathrm{mmHg}$. When the static pressure was $30 \mathrm{mmHg}$ (High hydrostatic pressure), $P_{d} P_{a}$ in case 2 was set as reconstructed iFR, and when the static pressure was $10 \mathrm{mmHg}\left(\right.$ Low hydrostatic pressure), $P_{d} P_{a}$ in case 2 was set as reconstructed FFR
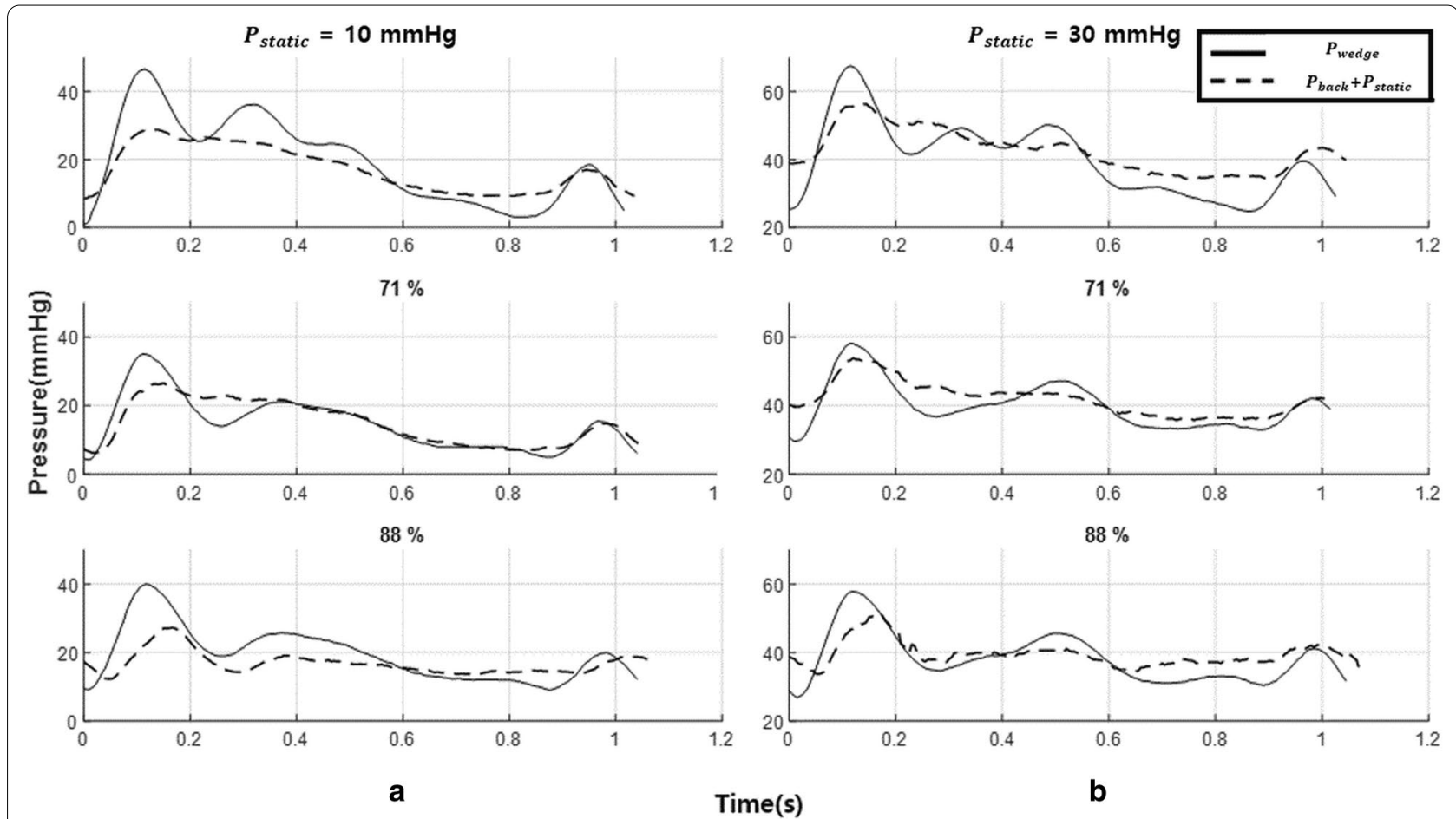

a

Time(s)

Fig. 5 The waveform of $P_{\text {wedge }}$ and $P_{\text {back. }}$. The static pressure was $\mathbf{a} 10$ and $\mathbf{b} 30 \mathrm{mmHg}$ at stenosis $48 \%$. Each static pressure was added to $P_{\text {back }}$ 


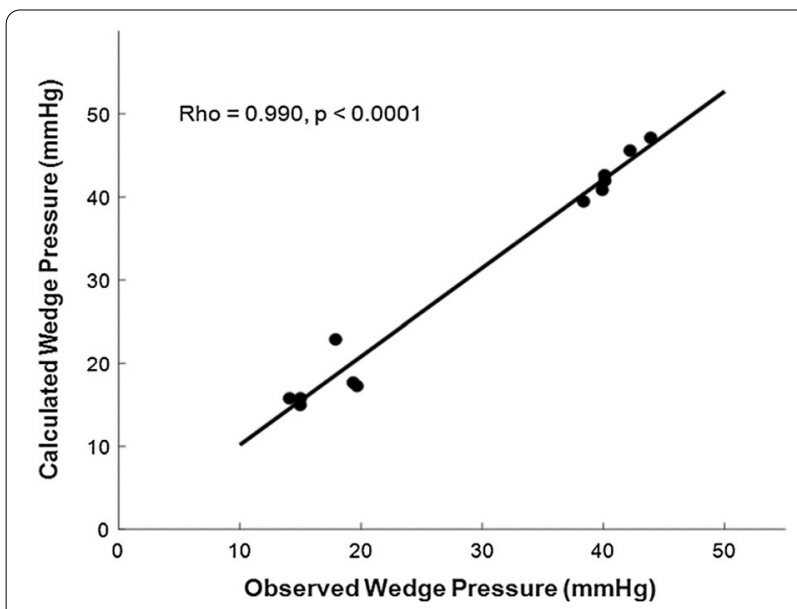

Fig. 6 The correlation between observed wedge pressure $\left(P_{\text {wedge }}\right)$ and calculated wedge pressure $\mathrm{P}_{\text {back }}+\mathrm{P}_{\text {static }}$. The correlation was high $(r=0.990, p<0.0001)$ and slope was 1.0612

The correlations between conventional FFR and reconstructed FFR and between conventional iFR and reconstructed iFR were positive $(\mathrm{r}=0.992, p<0.001$ and 0.930 , $p<0.001$, respectively; Fig. 7).

\section{Discussion}

In this study, coronary pressure waves could be separated into constituent forward $\left(\mathrm{P}_{\text {for }}\right)$ and backward $\left(\mathrm{P}_{\text {back }}\right)$ waves through WSA using frequency analysis. It could be said that $\mathrm{P}_{\text {back }}$ reflected $\mathrm{P}_{\text {wedge }}$ without $\mathrm{P}_{\text {static }}$ experimentally. It was shown that $F F R_{\text {cor }}$ and iFR could be expressed in trans-stenotic $\Delta \mathrm{P}_{\text {for }}$ either with or without hyperemia, which indicated that the two indices were inferred by removing $\mathrm{P}_{\text {wedge }}$ or $\mathrm{P}_{\text {back }}$. In vivo, $F F R_{\text {cor }}$ and iFR were reconstructed assuming that the $\mathrm{P}_{\text {back }}$ and $\mathrm{P}_{\text {wedge }}$ were similar. The reconstructed indices were highly correlated with the conventional ones. Therefore, to our knowledge, this study is the first to identify similarities and differences between $F F R_{\text {cor }}$ and iFR using WSA.

\section{Theoretical background of FFR and iFR through WSA}

In this study, $\mathrm{P}_{\text {back }}$ was characterized as undergoing rapid decline and forming baseline observed during pre-systole either with or without hyperemia. This finding is similar to the characteristics of $\mathrm{P}_{\text {wedge }}$ [5]. After forming the baseline of $\mathrm{P}_{b a c k}$, the slope of $\mathrm{P}_{f o r}$ was similar to the slope of coronary pressure. The period of forming the baseline of $\mathrm{P}_{\text {back }}$ was similar to the wave-free period. Eventually, the amplitude of $\mathrm{P}_{\text {for }}$ was smaller than the amplitude of coronary pressure (Fig. 1). During the wave-free period, $\mathrm{P}_{a}, \mathrm{P}_{d}$, and $\mathrm{P}_{\text {for }}$ could have the same slope because $\mathrm{P}_{\text {back }}$ for $\mathrm{ms}$ the baseline. The ratio between the lines with the same slope may be different, but the value in that interval is constant. iFR is defined as $\mathrm{P}_{d} / \mathrm{P}_{a}$ in the wavefree interval. Therefore, iFR may be related to $\mathrm{P}_{\text {for }}$ (distal)/ $\mathrm{P}_{\text {for }}$ (proximal) during the wave-free period. Furthermore, as the amplitude of $\mathrm{P}_{f o r}$ without $\mathrm{P}_{\text {back }}$ is low, the mean $\mathrm{P}_{f o r}$ of the whole cycle and the mean $\mathrm{P}_{f o r}$ of the wave-free period may be similar as a factor of ratio. As a result, in this study, reconstructed iFR was defined as $\mathrm{P}_{\text {for }}$ (distal)/ $\mathrm{P}_{\text {for }}$ (proximal) in Eq. 1. The reconstructed and conventional iFRs showed a good correlation based on in vivo results.

During hyperemia, the theoretical FFR of the coronary artery $\left(F F R_{c o r}\right)$ is $\left(P_{d}-P_{w}\right) /\left(P_{a}-P_{w}\right)$, while the FFR of the myocardium $\left(F F R_{m y o}\right)$ is $\left(P_{d}-P_{v}\right) /\left(P_{a}-P_{v}\right)$, where $P_{v}$ represents the mean central venous pressure [4]. The FFR is the ratio between mean values. A mean value is decreased when both the peak and the baseline are lowered. In this study, hyperemia mainly reduced the baseline of pressure (Fig. 1). Moreover, $\mathrm{P}_{\text {back }}$ was not zero but still decreased during hyperemia, and $\mathrm{P}_{\text {for }}$ was constant under the Windkessel effect.

The difference between $F F R_{c o r}$ and $F F R_{m y o}$ is described by collateral flow [4]. $\mathrm{P}_{\text {wedge }}$ is closely related to the collateral flow [19]. In addition, hyperemia theoretically reflects the offset of $\mathrm{P}_{\text {wedge }}$ and $P_{v}$ in the conventional FFRs [4]. However, the values of the $\mathrm{P}_{\text {wedge }}$ or $P_{v}$ would not be practically removed in hyperemia.

The FFR is based on the assumption that resistances both with and without stenosis are the same. Without collateral flow, this assumption implies that FFRmyo progressively overestimates the FFR using flow with increasing stenosis severity [4]. Thus, an attempt has been made to overcome this mismatch in reconstructing the FFR using zero flow pressure $\left(P_{z f}\right)$. The formula is as follows: FFR $=\left(P_{d}-P_{z f}\right) /\left(P_{a}-P_{z f}\right)$. FFR using $P_{z f}$ was in good agreement with the FFR using flow [20]. Because of the diastolic characteristics of the coronary arteries, $P_{z f}$ is independent of contraction and auto-regulation, showing conductance of the vessels and pure resistance [21-23]. However, $\mathrm{P}_{\text {wedge }}$ is generally smaller than $P_{z f}$ due to the non-linearity of the pressure-flow relationship and existence of cardiac contraction either with or without collateral flow [23-25]. Conceptually, $\mathrm{P}_{\text {back }}$ by WSA was similar to $P_{z f}$ in this study. This means that both FFR and iFR could be trans-stenotic $\Delta \mathrm{P}_{f o r}$, which can be expressed using the same formula, although their methods are different (Eqs. 1 and 2).

\section{Difference between FFR and iFR}

In order to replace the FFR using flow with FFR using pressure, hyperemia is required to offset $\mathrm{P}_{\text {wedge }}$ and $\mathrm{P}_{v}[4]$. As mentioned above, the reconstructed iFR was calculated by subtracting $\mathrm{P}_{\text {back }}$ at rest, which is assumed to be $\mathrm{P}_{\text {wedge }}$. Theoretically, $\mathrm{P}_{\text {for }}$ can be determined by the stroke 


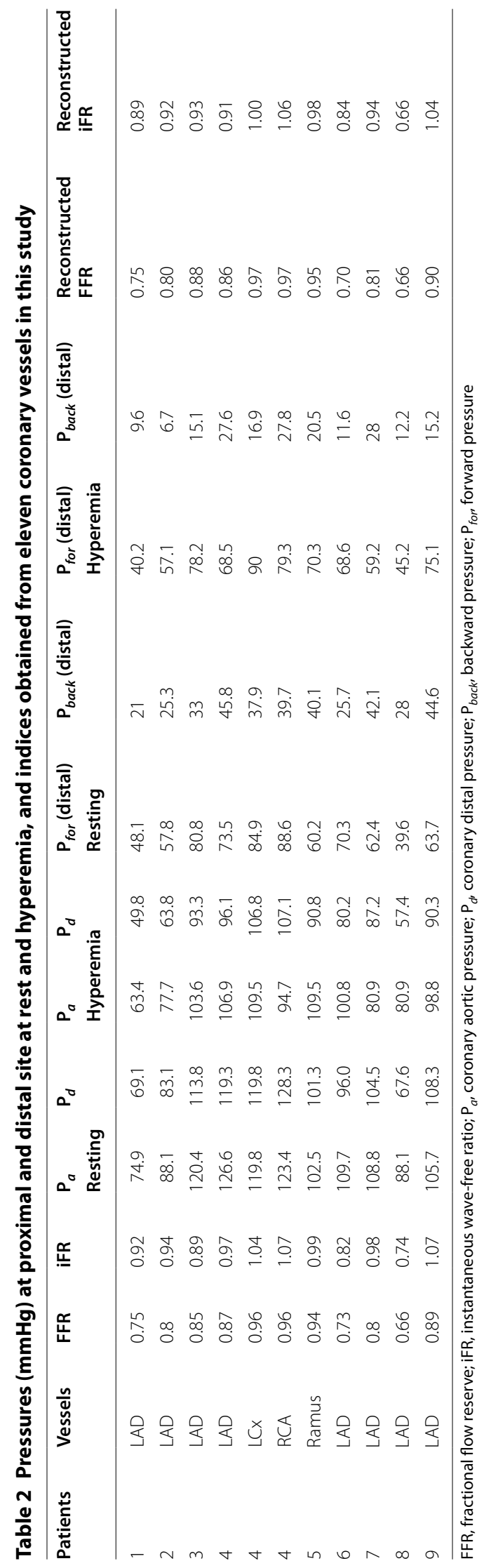



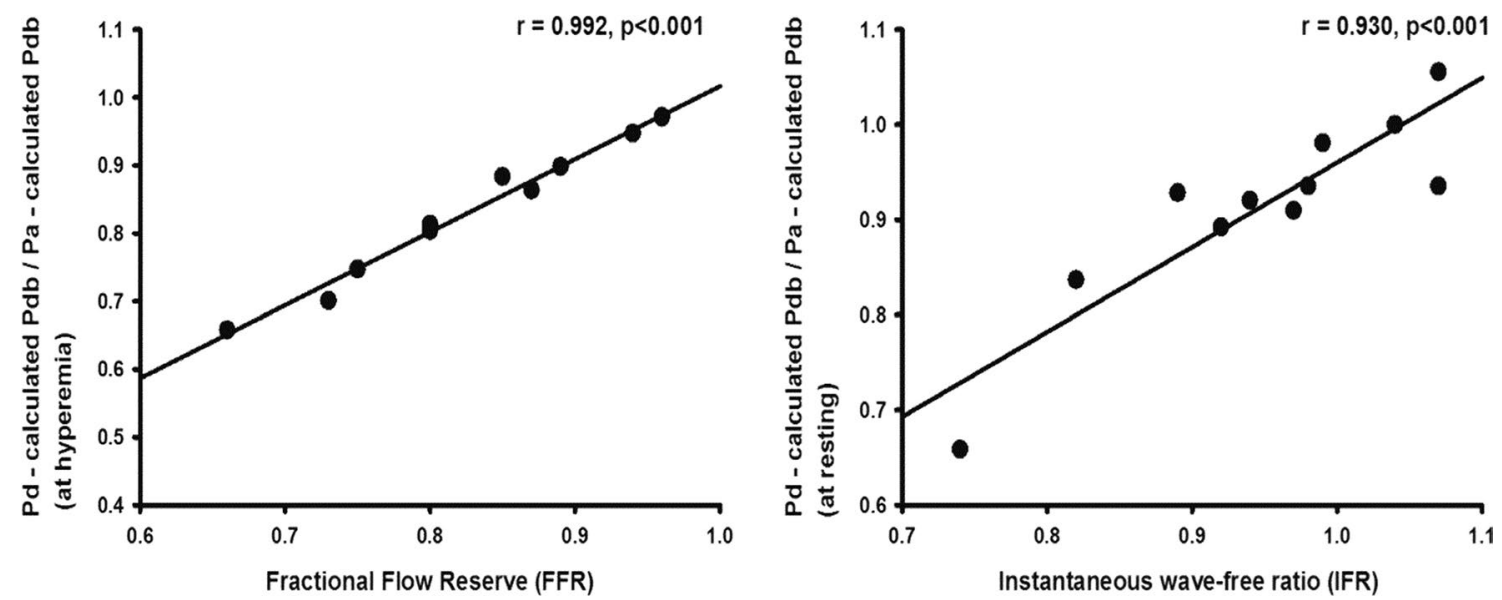

Fig. 7 Correlation between a FFR and reconstructed FFR, $\mathbf{b}$ iFR and reconstructed iFR. Both graphs show a high correlation

volume, which is related with inflow, resistance, compliance, and volume capacity, because the Windkessel effect is observed and systolic resistance by subtracting $\mathrm{P}_{\text {for }}$ is absent [8]. It is similar to systemic circulation. When administered for hyperemia, adenosine is reported to have little effect on the stroke volume or ejection fraction [26]. There is no significant change in blood volume without bleeding. Therefore, the difference in $\mathrm{P}_{\text {for }}$ with or without hyperemia is mainly dependent on resistance. The change of resistance according to the situation from rest to hyperemia could be the change of $\mathrm{P}_{\text {static }}$ or $\mathrm{P}_{v}$. Thus, the difference between iFR and FFR is likely to be the difference of $\mathrm{P}_{\text {for }}$ in relation to $\mathrm{P}_{\text {static }}$ or $\mathrm{P}_{v}$ rather than $\mathrm{P}_{\text {wedge }}$ or $\mathrm{P}_{\text {back }}$.

As myocardium oxygen consumption $\left(\mathrm{MVO}_{2}\right)$ increases due to enlargement of micro-vessels, resistance is reduced, and flow is increased. This trend is mainly regulated by the adenosine and nitric oxide $(\mathrm{NO})$ metabolites in the myocardium. In the presence of significant stenosis, the role of adenosine may be activated in microvessels, so the reactivity of hyperemia by adenosine may be lowered. In other words, resistance due to pharmacological hyperemia may be smaller in significant stenosis than in nonsignificant stenosis $[27,28]$.

\section{Clinical implications and future studies}

This is the first paper to prove that iFR and FFR are theoretically related using WSA up to our knowledge. The incidence of clinically appropriate hyperemia is not well known. In fact, it is difficult to verify hyperemia even with constant drug increases or drug changes. Thus, nonsignificant changes of $\mathrm{P}_{\text {for }}$ during hyperemia may be explained by the limitations of the assumption of constant resistance either with or without stenosis in FFR, and pharmacological hyperemia with inappropriate offsets of $\mathrm{P}_{\text {wedge }}$ and $\mathrm{P}_{v}$. Nevertheless, this study assumes that $\mathrm{P}_{f o r}$ is the primary factor for determining iFR and FFR using pressure. This assumption was confirmed by in vivo and in vitro results. Theoretically, the wave free period for iFR was made by WIA. The slope of $\mathrm{P}_{f o r}$ by WSA in the wave free period was similar to that of $\mathrm{P}_{a}$ and $\mathrm{P}_{d}$ in this period. Therefore, it will be possible to create a new algorithm of the wave free period for iFR.

\section{Limitation}

In this paper, we tried to reflect the characteristics of various coronary arteries such as blood flow and pressure waveforms, in the human body. There are many differences in blood flow and pressure waveforms in human coronary arteries. However, this variation did not pose a problem because we used the average values for pressure and blood flow.

It cannot be said that $\mathrm{P}_{\text {back }}$ reflects $\mathrm{P}_{\text {wedge }}$ experimentally. The constituent waves from WSA are the estimated values [10]. Moreover, the purpose of this study was to prove that iFR and FFR share the same formula. Therefore, the most important factors are morphological pattern and phase; acquiring accurate values was not the main goal. Accordingly, several trials of WSA were performed considering different $Z_{c}$ values. The results from various trials of WSA showed a similar pattern.

$\mathrm{Z}_{c}$ increased during hyperemia [14]. However, $\mathrm{Z}_{c}$ decreased in this study. Although this result cannot be explained, it is inferred that there are differences in the species or drugs used for hyperemia. To verify this hypothesis, additional experiments for $\mathrm{Z}_{c}$ will be needed.

The combo wire we used could measure pressure and flow at the catheter tip where Pd was measured. However, when measuring $\mathrm{Pa}$, the flow rate was not measured. Measurements in the proximal region were also not performed. So we could not calculate the proximal forward pressure 
using WSA. In a future study, the pressure and flow of the proximal site will be measured to check the separated pressure of the proximal and distal sites.

When measuring pressure and flow, we extracted one averaged cycle from more than 5 cycles based on the ECG signal. Groups with atrial fibrillation and other arrhythmia were excluded from the analysis. The process of finding $\mathrm{Z}_{c}$ for WSA may vary from person to person. Therefore, we made a program through Labview software to minimize the error of observers. Three investigators calculated the WSA using the software, and there was little error although the accuracy was not quantified.

\section{Conclusions}

In this study, we calculated $\mathrm{P}_{\text {back }}$ in the coronary artery using WSA and confirmed that the correlation between $\mathrm{P}_{\text {back }}$ and $\mathrm{P}_{\text {wedge }}$ was high. The FFR and iFR were reconstructed by reflecting $\mathrm{P}_{\text {wedge }}$ calculated through $\mathrm{P}_{\text {back }}$. It could be proved deductively that FFR and iFR can be expressed in the trans-stenotic $\Delta \mathrm{P}_{\text {for }}$. Therefore, the two indices are inferred from the same formula under different conditions. Similarities and differences between iFR and FFR were thus confirmed.

\section{Abbreviations}

FFR: Fractional flow reserve; iFR: Instantaneous wave-free ratio; $P_{\text {wedge: }}$ Wedge pressure; WSA: Wave separation analysis; WIA: Wave intensity analysis; $P_{\text {for }}$ : Forward pressure; $\mathrm{P}_{\text {back }}$ : Backward pressure; $\mathrm{P}_{d}$ : Distal pressure; $\mathrm{P}_{\text {for }}$ : Aortic pressure; $P_{\text {static }}$ Static pressure.

\section{Acknowledgements}

Parts of this study were presented to the ACC19(American College of Cardiology) conference under the titles "The reasons why fractional flow reserve and instance wave-free ration are similar using wave separation analysis" and "Implementation of coronary artery phantom with hyperemia".

\section{Authors' contributions}

SM performed validation experiment, analyzed the data, and was a major contributor in writing the manuscript. GK developed the software that calculated various pressure. DP conceived the in vitro experiments with supervision and provided the lab facilities and helped to draft the manuscript. JC designed and coordinated the study, conducted all clinical trials and helped to draft the manuscript. All authors read and approved the final manuscript.

\section{Funding}

SM and DP were supported by the National Research Foundation of Korea (NRF) grant funded by the Korea government (MSIT, No. 2018R1 A2B2007997), and GK and JC were supported by the research grant from Jeju National University and Jeju National University Hospital development fund. All funding was in the form of general financial support, which included staff salaries, travel, and publication fees. The funders played no role in the design of the study or in the collection, analysis, or interpretation of data or in writing the manuscript.

\section{Availability of data and materials}

The datasets used and/or analyzed during the current study are available from the corresponding author on reasonable request.

\section{Ethics approval and consent to participate}

Written consent was obtained from all participants, and the study protocol was approved by the institutional review board of Jeju National University Hospital (2016-07-011)
Consent for publication

Not applicable.

\section{Competing interests}

The authors declare no conflict of interest.

\section{Author details}

${ }^{1}$ Department of Ocean System Engineering, Jeju National University, Jeju, Korea. ${ }^{2}$ Division of Gastroenterology and Hepatology, Stanford University School of Medicine, Stanford, CA, USA. ${ }^{3}$ Department of Radiology and Medical Imaging, School of Medicine, University of Virginia, Charlottesville, VA, USA. ${ }^{4}$ Department of Cardiology, Jeju National University School of Medicine, Jeju National University Hospital, Jeju, Korea.

Received: 2 September 2020 Accepted: 6 January 2021

Published online: 25 January 2021

\section{References}

1. Fihn SD, Blankenship JC, Alexander KP, Bittl JA, Byrne JG, Fletcher BJ, et al. 2014 ACC/AHA/AATS/PCNA/SCAI/STS focused update of the guideline for the diagnosis and management of patients with stable ischemic heart disease: A report of the American College of Cardiology/American Heart Association Task Force on Practice Guidelines, and the American Association for Thoracic Surgery, Preventive Cardiovascular Nurses Association, Society for Cardiovascular Angiography and Interventions, and Society of Thoracic Surgeons. J Am Coll Cardiol. 2014;64(18):1929-49.

2. Götberg M, Christiansen EH, Gudmundsdottir IJ, Sandhall L, Danielewicz $M$, Jakobsen $L$, et al. Instantaneous wave-free ratio versus fractional flow reserve to guide PCI. N Engl J Med. 2017;376(19):1813-23.

3. Davies JE, Sen S, Dehbi H, Al-Lamee R, Petraco R, Nijjer SS, et al. Use of the instantaneous wave-free ratio or fractional flow reserve in $\mathrm{PCI}$. N Engl J Med. 2017;376(19):1824-34.

4. Pijls NH, van Son JA, Kirkeeide RL, De Bruyne B, Gould KL. Experimental basis of determining maximum coronary, myocardial, and collateral blood flow by pressure measurements for assessing functional stenosis severity before and after percutaneous transluminal coronary angioplasty. Circulation. 1993;87(4):1354-67.

5. Pacold I, Hwang MH, Piao ZE, Scanlon PJ, Loeb HS. The mechanism and significance of ventricularization of intracoronary pressure during coronary angiography. Am Heart J. 1989;1 18(6):1161.

6. Westerhof N, Segers P, Westerhof BE. Wave separation, wave intensity, the reservoir-wave concept, and the instantaneous wave-free ratio: presumptions and principles. Hypertension. 2015;66(1):93-8.

7. Davies J, Whinnett Z, Francis D, Manisty C, Guado-Sierra J, Willson K, et al. evidence of a dominant backward-propagating "suction" wave responsible for diastolic coronary filling in humans, attenuated in left ventricular hypertrophy. Circulation. 2006;113:1768-78.

8. Westerhof N, Lankhaar J, Westerhof BE. The arterial Windkessel. Med Biol Eng Comput. 2009;47(2):131-41.

9. O'Rourke MF, Taylor MG. Input impedance of the systemic circulation. Circ Res. 1967;20(4):365-80.

10. O'Rourke MF, Hartley C, McDonald DA. McDonald's blood flow in arteries: theoretic, experimental, and clinical principles. London: Arnold; 1998.

11. Bergel DH, Milnor WR. Pulmonary vascular impedance in the dog. Circ Res. 1965;16(5):401-15.

12. Milnor WR, Bertram CD. The relation between arterial viscoelasticity and wave propagation in the canine femoral artery in vivo. Circ Res. 1978;43(6):870-9

13. Stergiopulos $N$, Westerhof $B E$, Westerhof $N$. Total arterial inertance as the fourth element of the Windkessel model. Am J Physiol Heart Circ Physiol. 1999;276(1):H81-8.

14. Van Huis GA, Sipkema P, Westerhof N. Coronary input impedance during cardiac cycle as determined by impulse response method. Am J Physiol. 1987;253(2 Pt 2):H317-24.

15. Cox RH, Bagshaw RJ. Baroreceptor reflex control of arterial hemodynamics in the dog. Circ Res. 1975;37(6):772-86.

16. Kern MJ, Lerman A, Bech J, De Bruyne B, Eeckhout E, Fearon WF, et al. Physiological assessment of coronary artery disease in the cardiac catheterization laboratory: A scientific statement from the American 
Heart Association Committee on Diagnostic and Interventional Cardiac Catheterization, Council on Clinical Cardiology. Circulation. 2006;114(12):1321-41.

17. Choi JH, Davies J, Cook C, Sen S, Nijjer S, Da Cunha RP, Al-Lamee R, Ahmad $Y$. The reasons why fractional flow reserve and instance wavefree ration are similar using wave separation analysis. J Am Coll Cardiol. 2019;73(9S1):152-152

18. Min SH, Lee C, Lee J, Kang G, Paeng DG, Choi JH. Implementation of coronary artery phantom with hyperemia. J Am Coll Cardiol. 2019;73(9S1):153-153.

19. Mohri M, Egashira K, Kuga T, Shimokawa H, Takeshita A. Correlations between recruitable coronary collateral flow velocities, distal occlusion pressure, and electrocardiographic changes in patients undergoing angioplasty. Jpn Circ J. 1997;61(12):971-8.

20. Claessens TE, Van Herck PL, Matthys KS, Segers P, Vrints CJ, Verdonck PR. Influence of zero flow pressure on fractional flow reserve. Biomech Model Mechanobiol. 2004;3(1):48-55.

21. Bellamy RF. Diastolic coronary artery pressure-flow relations in the dog. Circ Res. 1978;43(1):92-101.

22. Mancini GB, McGillem MJ, DeBoe SF, Gallagher KP. The diastolic hyperemic flow versus pressure relation. A new index of coronary stenosis severity and flow reserve. Circulation. 1989;80(4):941-50.

23. Spaan JA, Piek JJ, Hoffman JI, Siebes M. Physiological basis of clinically used coronary hemodynamic indices. Circulation. 2006;113(3):446-55.
24. Messina LM, Hanley FL, Uhlig PN, Baer RW, Grattan MT, Hoffman J. Effects of pressure gradients between branches of the left coronary artery on the pressure axis intercept and the shape of steady state circumflex pressure-flow relations in dogs. Circ Res. 1985;56(1):11-9.

25. Downey JM, Kirk ES. Inhibition of coronary blood flow by a vascular waterfall mechanism. Circ Res. 1975;36(6):753-60.

26. Ogilby JD, Iskandrian AS, Untereker WJ, Heo J, Nguyen TN, Mercuro J. Effect of intravenous adenosine infusion on myocardial perfusion and function. Hemodynamic/angiographic and scintigraphic study. Circulation. 1992;86(3):887-95.

27. Gould KL, Lipscomb K, Hamilton GW. Physiologic basis for assessing critical coronary stenosis: Instantaneous flow response and regional distribution during coronary hyperemia as measures of coronary flow reserve. Am J Cardiol. 1974;33(1):87-94.

28. Gould KL, Kirkeeide RL, Buchi M. Coronary flow reserve as a physiologic measure of stenosis severity. J Am Coll Cardiol. 1990:15(2):459-74.

\section{Publisher's Note}

Springer Nature remains neutral with regard to jurisdictional claims in published maps and institutional affiliations.
Ready to submit your research? Choose BMC and benefit from:

- fast, convenient online submission

- thorough peer review by experienced researchers in your field

- rapid publication on acceptance

- support for research data, including large and complex data types

- gold Open Access which fosters wider collaboration and increased citations

- maximum visibility for your research: over $100 \mathrm{M}$ website views per year

At $\mathrm{BMC}$, research is always in progress.

Learn more biomedcentral.com/submissions 